\title{
Seroprevalence of Dengue, Zika, and Chikungunya Viruses in Wild Monkeys in Thailand
}

\author{
Daraka Tongthainan, ${ }^{1}$ Nanthanida Mongkol, ${ }^{2}$ Kultida Jiamsomboon, ${ }^{2}$ Sarocha Suthisawat, ${ }^{2}$ Pornchai Sanyathitiseree, ${ }^{3}$ \\ Manakorn Sukmak, ${ }^{4}$ Worawidh Wajjwalku, ${ }^{5}$ Yong Poovorawan, ${ }^{6}$ Gittiyaporn leamsaard, ${ }^{7}$ Bencharong Sangkharak, ${ }^{7}$ \\ Kanokwan Taruyanon, ${ }^{7}$ Wirasak Fungfuang, ${ }^{8}$ Phitsanu Tulayakul, ${ }^{9}$ and Kobporn Boonnak ${ }^{2 \star}$ \\ ${ }^{1}$ Bio-Veterinary Sciences Program, Faculty of Veterinary Medicine, Kasetsart University, Bangkok, Thailand; ${ }^{2}$ Department of Microbiology and \\ Immunology, Faculty of Tropical Medicine, Mahidol University, Bangkok, Thailand; ${ }^{3}$ Department of Livestock and Wildlife Medicine, Faculty of \\ Veterinary Medicine, Kasetsart University, Bangkok, Thailand; ${ }^{4}$ Department of Farm Resources and Production Medicine, Faculty of Veterinary \\ Medicine, Kasetsart University, Bangkok, Thailand; ${ }^{5}$ Faculty of Veterinary Medicine, Kasetsart University, Bangkok, Thailand; ${ }^{6}$ Center of Excellence \\ in Clinical Virology, Faculty of Medicine, Chulalongkorn University, Bangkok, Thailand; ${ }^{7}$ Department of National Park Wildlife and Plant \\ Conservation, Bangkok, Thailand; ${ }^{8}$ Department of Zoology, Faculty of Science, Kasetsart University, Bangkok, Thailand; ${ }^{9}$ Department of Veterinary \\ Public Health, Faculty of Veterinary, Kasetsart University, Thailand
}

\begin{abstract}
Zoonotic pathogens such as arboviruses have comprised a significant proportion of emerging infectious diseases in humans. The role of wildlife species as reservoirs for arboviruses is poorly understood, especially in endemic areas such as Southeast Asia. This study aims to determine the exposure history of different macaque species from national parks in Thailand to mosquito-borne flaviviruses and alphavirus by testing the serum samples collected from 25 northern pigtailed macaques, 33 stump-tailed macaques, and 4 long-tailed macaques for the presence of antibodies against dengue, Zika, and chikungunya viruses by plaque reduction neutralization assay. Specific neutralizing antibodies against Dengue virus (DENV1-4) and Zika virus (ZIKV) were mainly found in stump-tailed macaques, whereas neutralizing antibody titers were not detected in long-tailed macaques and pigtailed macaques as determined by $90 \%$ plaque reduction neutralization assay $\left(\mathrm{PRNT}_{90}\right)$. One long-tailed macaque captured from the south of Thailand exhibited antibody titers against chikungunya virus (CHIKV), suggesting enzootic of this virus to nonhuman primates (NHPs) in Thailand. Encroachment of human settlements into the forest has increased the interface that exposes humans to zoonotic pathogens such as arboviruses found in monkeys. Nonhuman primates living in different regions of Thailand showed different patterns of arboviral infections. The presence of neutralizing antibodies among wild monkeys in Thailand strongly suggests the existence of sylvatic cycles for DENV, ZIKV, and CHIKV in Thailand. The transmission of dengue, Zika, and chikungunya viruses among wild macaques may have important public health implications.
\end{abstract}

\section{INTRODUCTION}

Several important and emergent arboviruses such as dengue (DENV), Zika (ZIKV), and chikungunya (CHIKV) originated from nonhuman primates (NHPs). ${ }^{1}$ In the natural forest habitats of NHPs, mosquitoes transmit arboviruses from infected to naive animals in a process termed the sylvatic transmission cycle. Humans increase the risk of infection through hunting, deforestation, agriculture, and urbanization and can become infected when bitten by an infected mosquito carrying arboviruses into human residential areas when looking to obtain a blood meal. The sylvatic transmission cycle is then believed to have "spilled over" into an urban transmission cycle..$^{2-4}$ Arboviruses such as DENV, ZIKV, and CHIKV have become fully adapted to urban cycles. They no longer require NHPs, forest mosquitoes, and the sylvatic cycle to maintain their transmission cycles. ${ }^{5}$ However, the sylvatic cycle may act as a reservoir for arboviruses, which enables reemergence once human epidemics have passed and herd immunity has waned. Moreover, the sylvatic cycle might provide selective environments where new strains of arboviruses can develop with increased or decreased virulence toward humans. Although outbreaks of arboviruses are frequently reported in Southeast Asia, the intensive study on the potential role of NHPs in the transmission of arboviruses is limited, especially in Thailand. Infected NHPs typically show no clinical signs of infection but become viremic and help to maintain the viruses in nature, ${ }^{3}$ resulting in the difficulty to assess the potential role of NHPs in

\footnotetext{
*Address correspondence to Kobporn Boonnak, Department of Microbiology and Immunology, Faculty of Tropical Medicine, Mahidol University, 420/6 Ratchawithi Rd. Ratchathewi, Bangkok 10400,
} Thailand. E-mail: kobporn.boo@mahidol.ac.th the field when detecting viral genomes in NHP serum samples. However, an alternative strategy to identify potential reservoirs of arboviruses is to detect the antibody response in animals captured in the field. ${ }^{6}$ Herein, this study investigated the potential role of natural free-living NHPs in DENV-, ZIKV-, and CHIKV-endemic areas by conducting a serological study using serum samples collected from 25 northern pigtailed macaques (Macaca leonina), 33 stump-tailed macaques (Macaca arctoides), and 4 long-tailed macaques (Macaca fascicularis) living in Khao Yai, Kaeng Krachan, and Mu Ko Ranong national parks, Thailand, respectively. To assess the neutralizing antibody against DENV1-4, ZIKV, and CHIKV, the high stringent $90 \%$ plaque reduction neutralization assay ( PRNT $_{90}$ ) was performed in this study.

\section{MATERIALS AND METHODS}

Ethical statement. This study was approved by the Institutional Animal Care and Use Committee of Kasetsart University, Thailand (approval number: ACKU60-VET-049).

Monkey blood collection. Sixty-two monkey serum samples were used in this study. Twenty-five M. leoninia serum samples were collected from Khao Yai National Park, Nakhon Ratchasima, in October 2018; 33 M. arctoides serum samples were collected from Kaeng Krachan National Park, Phetchaburi, in December 2018; and 4 M. fascicularis serum samples were collected from Mu Ko Ranong National Park, Ranong, in January 2019 (Figure 1). The monkeys were captured using a ground trap. The monkeys were sedated with Zoletil ${ }^{\circledR}$ (Virbac, Hamilton, New Zealand) (tiletamine and zolazepam) $(2-10 \mathrm{mg} / \mathrm{kg})$ and xylazine $\mathrm{HCl}(0.5-2 \mathrm{mg} / \mathrm{kg})$ administered intramuscularly. Anthropological measurements were taken (weight, arm length, leg length, tail length, and body length), 


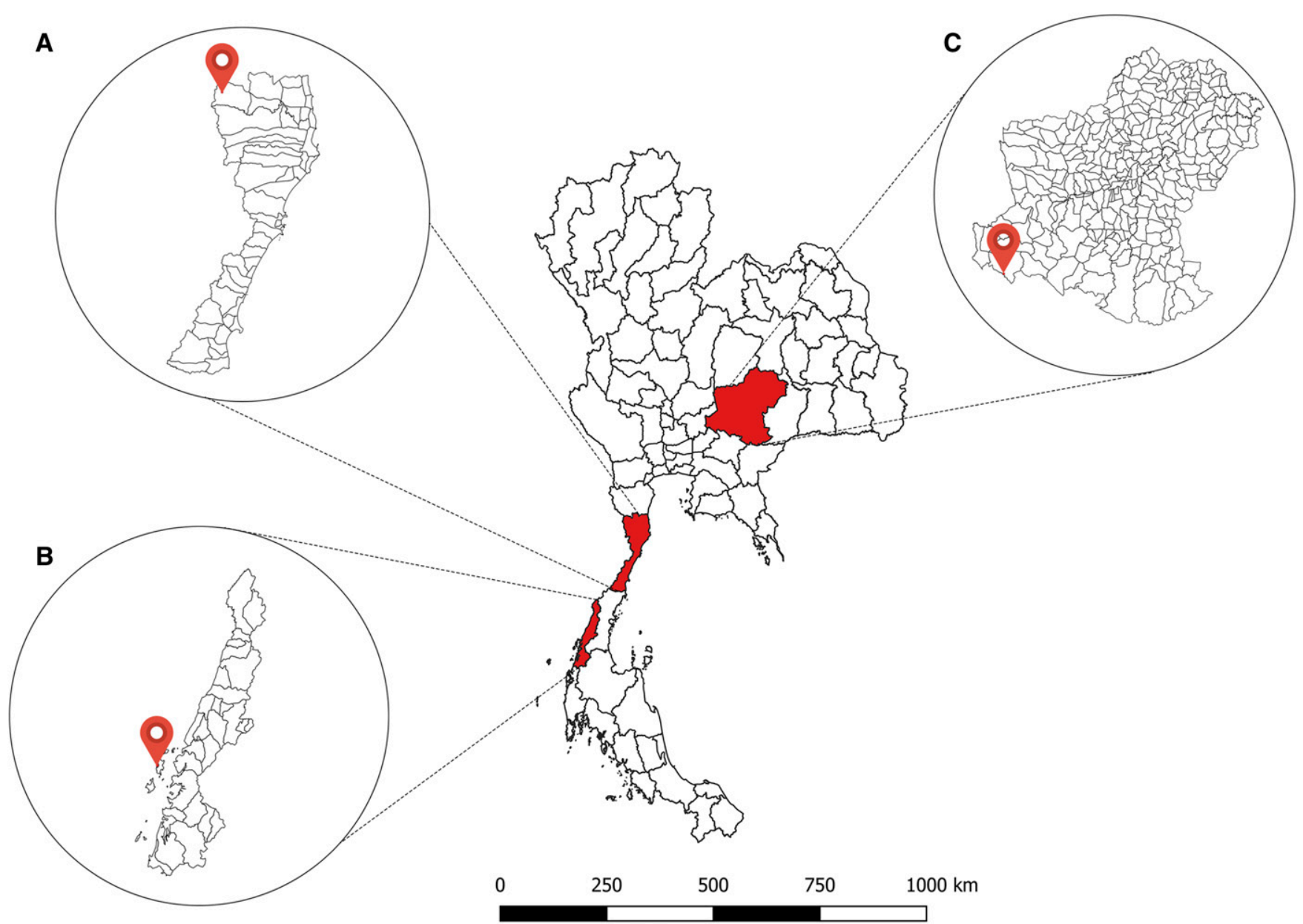

FIGURE 1. Monkey collection sites in Thailand. (A) Kaeng Krachan National Park, Prachuap Khiri Khan (GPS: 12.240800, 99.464004). (B) Mu Ko Ranong National Park, Ranong (GPS: 9.838183, 98.436467). (C) Khao Yai National Park, Nakhon Ratchasima (GPS: 14.444504, 101.376237). This figure appears in color at www.ajtmh.org.

and gender was determined. Dental casts and dental photographs were taken. Monkeys were bled from the inguinal vein while sedated, and serum samples were stored at $-80^{\circ} \mathrm{C}$.

Viruses and cells. Vero (WHO) cell line and DENV1 (WP), DENV2 (NGC), DENV3 (7164), DENV4 (7-4A-1A2), and ZIKV (Paraiba/2015) were provided by Dr. Stephen Whitehead (NIAID, NIH, USA). The Vero cells were maintained in minimal essential medium (Invitrogen, Carlsbad, CA) supplemented with 10\% fetal bovine serum (Life Technology, Grand Island, NY). Chikungunya (TM-006/2019) was amplified and titrated on Vero cell monolayer.

Serology assessment. Neutralizing antibodies to DENV1-4, Zika, and CHIKV were determined by $90 \%$ plaque reduction neutralization (PRNT 90 ) assays, using the lowest serum dilution that gave a $90 \%$ reduction of viral foci as described. ${ }^{7,8}$ Briefly, test sera were heat-inactivated at $56^{\circ} \mathrm{C}$ for 30 minutes, and serial 4-fold dilutions beginning at 1:5 were diluted with serum diluent OptiMEM (Invitrogen) supplemented with 0.3\% human serum albumin (Sigma-Aldrich, St. Louis, MO). Dengue virus 1-4 and Zika virus, diluted to a final concentration of 1,000 $\mathrm{pfu} / \mathrm{mL}$ in serum diluent, were added to equal volumes of the diluted serum and mixed well. The virus/serum mixture was incubated at $37^{\circ} \mathrm{C}$ for 30 minutes. Cell culture medium was removed from $90 \%$ confluent monolayer of Vero cells on 24- well plates, and $50 \mu \mathrm{L}$ of the virus-serum mixture was transferred onto duplicate wells of cell monolayers. Cell monolayers were incubated for 60 minutes at $37^{\circ} \mathrm{C}$ and overlaid with $0.5 \%$ methylcellulose in OptiMEM supplemented with $2 \%$ FBS. Samples were incubated at $37^{\circ} \mathrm{C}$ for 3 and 4 days for Zika and DENV viruses, respectively. Plaques were visualized by immunoperoxidase staining. Methylcellulose was removed from infected monolayers, and cells were fixed in $80 \%$ methanol for 30 minutes and rinsed with $5 \%$ nonfat milk in phosphate buffer saline (PBS). The 4G2 (mouse anti-Flavivirus envelope protein antibody, which bind to a conserved epitope $E$ protein of the Flavivirus family ${ }^{9}$ ) and $2 \mathrm{H} 2$ (mouse anti-DENV1-4 prM protein $^{10}$ ) monoclonal antibodies (provided by Dr. Steve Whitehead, NIAID, NIH) were diluted 1:2,000 in 5\% nonfat milk and added to each well followed by a 1 hour incubation at room temperature. Primary antibodies were removed, and the cell monolayers were washed twice with PBS. Peroxidase-labeled goat anti-mouse IgG (Kirkegaard and Perry Laboratories, Gaithersburg, MD) was diluted 1:2,000 in 5\% nonfat milk and added to each well, followed by 1 hour incubation at $37^{\circ} \mathrm{C}$. Secondary antibodies were removed, and the wells were washed twice with PBS. Peroxidase substrate (4-chloro-1naphthol in $\mathrm{H}_{2} \mathrm{O}_{2}$ ) was added to each well, and visible plaques were counted. For detection of CHIKV-neutralizing antibodies, 
the CHIKV, diluted to a final concentration of $1,000 \mathrm{PFU} / \mathrm{mL}$ in the serum diluent, was then added to equal volumes of the diluted serum samples. The virus-serum mixture was incubated at $37^{\circ} \mathrm{C}$ for 30 minutes. Cell culture medium was removed from $90 \%$ confluent monolayer of Vero cell on 24-well plates, and $100 \mu \mathrm{L}$ of the virus-serum mixture was added to duplicate wells and incubated for 1 hour at $37^{\circ} \mathrm{C}$ and overlaid with $0.5 \%$ methylcellulose in OptiMEMGlutaMAX supplemented with $2 \%$ FBS. Samples were incubated at $37^{\circ} \mathrm{C}$ for 3 days. The plaques were visualized by staining with $0.2 \%$ crystal violet (Sigma-Aldrich). The PRNT titer is calculated based on a $90 \%$ reduction in plaque counts (PRNT 90 ) using a curve-fitting method, ${ }^{8}$ which is an online program developed by NIH/NIAID (https://bioinformatics.niaid.nih.gov/plaquereduction). To use the $\mathrm{PRNT}_{90}$ antibody titers to differentiate ZIKV infection from other flavivirus infections, $\mathrm{PRNT}_{90}$ test results were interpreted using the WHO criteria. ${ }^{11,12}$ The WHO criteria classify ZIKV infection as samples with $\mathrm{PRNT}_{90}$ titer values $\geq 20$ and a 4-fold difference between ZIKV and DENV PRNT ${ }_{90}$ titers.

\section{RESULTS}

Monkeys were captured at three national parks in central, northeastern, and southern Thailand (Figure 1). Blood samples were collected from three groups of NHPs: 25 northern pigtailed macaques (14 males and 11 females) from Khao Yai National Park, 33 stump-tailed macaques ( 25 males and eight females) from Kaeng Krachan National Park, and 4 long-tailed macaques (two males and two females) from Mu Ko Ranong National Park in 2018. Most serum samples were collected from adult macaques in all three national parks (Table 1).

The prevalence of DENV, ZIKV, and CHIKV was assessed in all monkey serum samples collected from the three study locations. None of the serum samples tested positive for viral RNA in the genus-specific nested reverse transcription-PCR (RT-PCR) assay targeting DENV1-4 nor the highly sensitive strain-specific real-time RT-PCR assay for ZIKV and CHIKV (data not shown). The results suggest the absence of an acute infection of DENV, ZIKV, and CHIKV in all animals from three study locations. Therefore, the prevalence of prior DENV1-4, ZIKV, and CHIKV infections was assessed by $90 \%$ plaque reduction neutralization assay (PRNT 90 ). Neutralizing antibody titers of greater than or equal to 1:20 were considered positive according to the WHO criteria. ${ }^{11,12}$ None of the northern pigtailed macaque samples from Khao Yai National Park had neutralizing antibodies against DENV4, DENV3, and DENV1. Low-level neutralizing antibody titers $(<20)$ were observed in long-tailed macaque serum samples collected from Mo Ko Ranong National Park. Neutralizing antibodies against DENV2 were detected in two of four samples (50\%). In addition, 17 of 33 stump-tailed macaque serum samples from Kaeng Krachan National Park had neutralizing antibodies to
DENV as assessed by PRNT 90 assay (titer $\geq 20$ ). Of these 17 samples, $76.5 \%$ (13 of 17 ), $88.2 \%$ (15 of 17 ), $58.8 \%$ (10 of 17 ), and $23.5 \%$ (4 of 17 ) had neutralizing antibody titers against DENV1, DENV2, DENV3, and DENV4, respectively (Figure 2 and Supplemental Table 1). Because historical evidence has indicated that ZIKV and CHIKV epidemiology includes a sylvatic cycle involving NHPs, ${ }^{5,13,14}$ the antibodies against ZIKV and $\mathrm{CHIKV}$ in these macaques were also determined. None of the northern pigtailed macaques from Khao Yai National Park and long-tailed macaques captured from Mo Ko Ranong National Park exhibited antibodies against ZIKV. However, neutralizing antibody titers against ZIKV $(\geq 20)$ were observed in 6 of 33 stump-tailed macaque serum samples (18\%) collected from Kaeng Krachan National Park. However, only one monkey had the ZIKV PRNT 90 titer value $=20.4$ with PRNT $_{90}$ titer values $<5$ for DENV1-4, which may indicate ZIKV infection in monkeys living in this area. In addition, a high titer of anti-CHIKV was detected in a serum sample of a long-tailed macaque obtained from Mo Ko Ranong National Park but not in macaque serum samples from the other study sites (Figure 2 and Supplemental Table 1).

\section{DISCUSSION}

Dengue virus, ZIKV, and CHIKV are maintained in two ecologically and evolutionarily distinct transmission cycles, which include a sylvatic cycle and an urban cycle. ${ }^{5,15-18} \mathrm{Sci-}$ entific evidence strongly suggests that DENV, ZIKV, and $\mathrm{CHIKV}$ have the potential to shift from an animal reservoir into humans, with the main animal reservoir being NHPs. ${ }^{2} \mathrm{Al}-$ though macaques are ubiquitous in moderately to heavily human-populated areas around Southeast Asia and tend to have heavy human interaction around tourist areas, the potential role of NHPs on arboviral transmission is not intensively studied. The present study aims to determine arboviral infections within national parks of Thailand where forest-living macaques occasionally come into contact with humans when seeking for food at tourist visiting centers. In this study, the broad spectrum of anti-DENV1-4 was observed among monkey species in the location of the natural habitats. AntiZIKV was detected in the stump-tailed macaques but not in the other species. In addition, one of four long-tailed macaques living in the south of Thailand was found to possess a specific antibody against $\mathrm{CHIKV}$. Results demonstrated a high prevalence of neutralizing antibodies against multiple arboviruses in wild monkeys in Thailand.

No evidence of active DENV, ZIKV, and CHIKV infections was found in all macaque serum samples. No active infections observed in these monkeys may have resulted from the difficulty in collecting serum samples from macaques at peak viremia as they do not present disease symptoms, and the

TABLE 1

Monkey collection

\begin{tabular}{|c|c|c|c|c|}
\hline Region & Specie & $N$ & Gender & Age group \\
\hline Khao Yai National Park & Macaca leonina & 25 & $\begin{array}{l}\text { Male }=14 \\
\text { Female }=11\end{array}$ & $\begin{array}{l}\text { Juvenile }=7 \\
\text { Adult }=18\end{array}$ \\
\hline Kaeng Krachan National Park & Macaca arctoides & 33 & $\begin{array}{l}\text { Male }=25 \\
\text { Female }=8\end{array}$ & $\begin{array}{l}\text { Juvenile }=2 \\
\text { Adult }=31\end{array}$ \\
\hline Mu Ko Ranong National Park & Macaca fascicularis & 4 & $\begin{array}{l}\text { Male }=2 \\
\text { Female }=2\end{array}$ & $\begin{array}{l}\text { Juvenile }=2 \\
\text { Adult }=2\end{array}$ \\
\hline
\end{tabular}




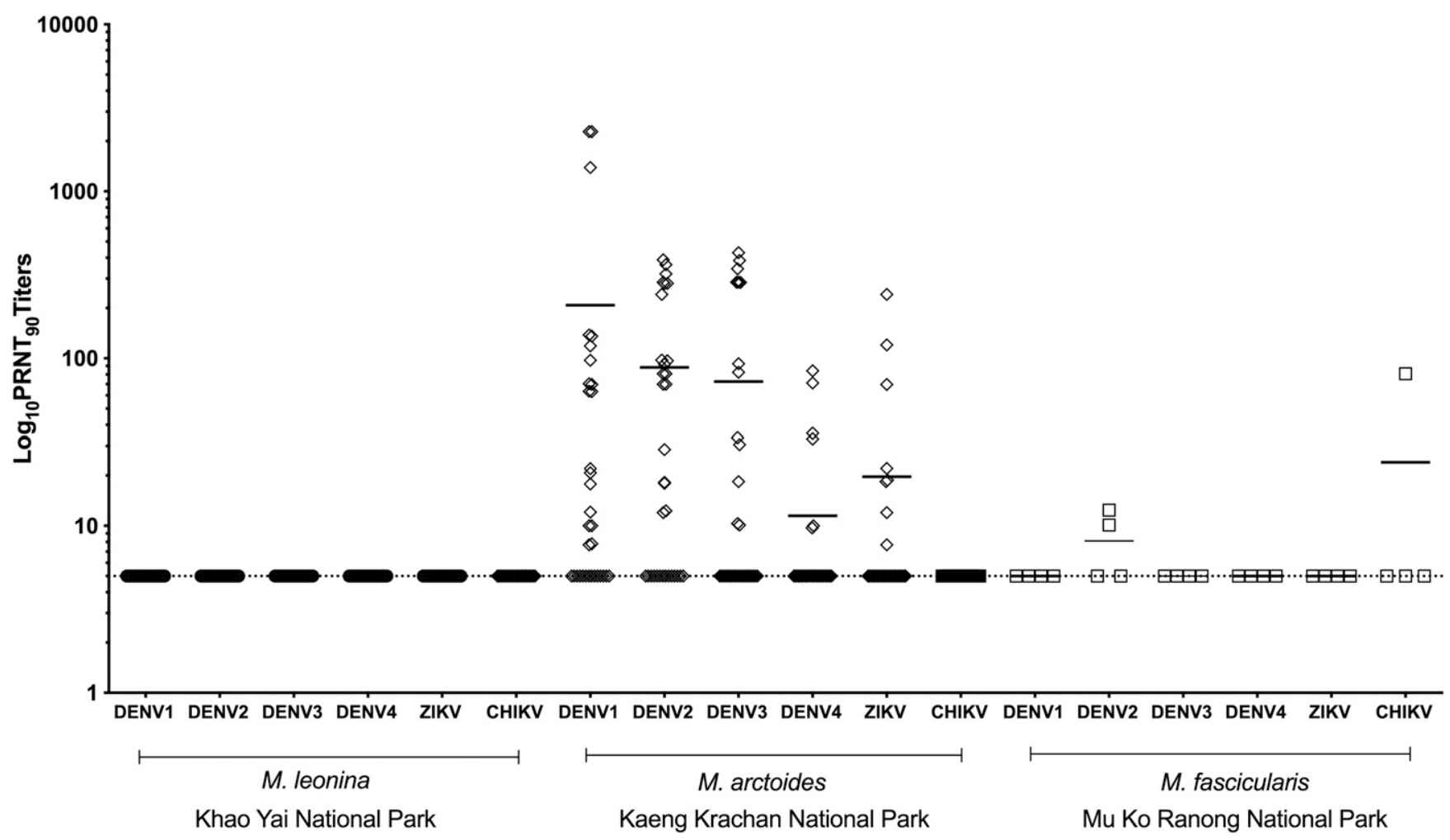

FIGURE 2. Dengue virus1-4, Zika virus- and chikungunya virus-neutralizing antibody titers in Macaca leonina, Macaca arctoides, and Macaca fascicularis from Khao Yai, Kaeng Krachan, and Mu Ko Ranong National Parks, respectively. The initial serum dilution in this assay was 1:5, and seropositivity was defined as a $\mathrm{PRNT}_{90} \geq 1: 20$.

arboviral viremias are only short lived, from 1 to 7 days. ${ }^{19-22}$ Therefore, serology was used to explore the possible sylvatic transmission as antibodies are able to indicate previous exposures to DENV, ZIKV, and CHIKV in these macaques. By using high stringent $\mathrm{PRNT}_{90}$ to determine neutralizing antibody titers to DENV, ZIKV and CHIKV, DENV antibody titers $(\geq 20)$ were observed in the stump-tailed macaque serum samples. By contrast, none of sera collected from pigtailed and long-tailed macaques showed antibody titers greater than $1: 20$. In contrast to the results of a previous study whereby that $23 \%$ of northern pigtailed macaques from a national park located in the north of Thailand had antibodies against DENV, ${ }^{23}$ none of the pigtailed macaques in our study had neutralizing antibodies to DENV, ZIKV, and CHIKV greater than 1:20. The discrepancy may have resulted from different methods used for determining antibody titers, as our study used PRNT 90 and the other study used PRNT 50 . Low DENV antibody titers observed in long-tailed macaques may indicate the previous exposure to DENV a number of years prior. By contrast, very high levels of DENV antibodies detected in stump-tailed macaques suggest recent infection or repeated exposure of these monkeys to DENV in Kaeng Krachan National Park areas. According to information from the national disease surveillance system, MoPH Thailand (http://www.boe.moph.go.th), DENV1 and DENV2 were the most prevalent circulating serotypes in humans in Thailand during 2018-2019. In agreement with DENV activity in humans, we observed high levels of seroprevalence of DENV1 and DENV2 in macaques living in Kaeng Krachen National Park and Mo Ko Ranong National Park. These findings raise awareness of the possibility of transmission between humans and NHPs via mosquito vectors in Thailand, which have also been previously reported by other investigators. ${ }^{24,25}$ These results also suggest that the distribution of DENV infection may be determined by host species, similar to previous reports by several researchers. The susceptibility of NHPs may also result from other factors such as environmental or geographical factors, such as the dominance of particular mosquito vectors, and host species. However, further research needs to be carried out to substantiate this hypothesis.

Zika virus and CHIKV were both originally isolated from NHPs in Africa, and recent studies have described the probable role of NHPs as reservoir and amplification hosts of the arboviruses. ${ }^{14,18}$ Low seroprevalence rates of ZIKV antibodies in long-tailed macaques suggest that long-tailed macaques are unlikely to be reservoirs for ZIKV in Malaysia. ${ }^{26}$ However, ZIKV serosurveys have not been assessed in Thailand. Therefore, this study assessed the levels of antibodies against ZIKV and CHIKV in these monkeys. High titers against ZIKV were also detected in stump-tailed macaque serum samples collected from Kheang Krachan National Park. Although the phylogenetic analysis of ZIKV strains collected from patients with PCR-confirmed infection provided evidence of ZIKV circulation in Thailand since at least $2002,{ }^{27}$ the ZIKV-infected cases were not formally reported nearby our studied sites (http://www.boe.moph.go.th). Therefore, our data which showed the presence of ZIKV antibodies in NHPs in Kaeng Krachen National Park will help raise awareness about ZIKV circulation in the area and the possibility of spillover events that could be initiated to human populations living in the 
proximity. However, the well-described problem in assessing ZIKV seroprevalence is the cross-reactivity of antibodies to other flaviviruses. ${ }^{28}$ The ZIKV antibodies observed in the monkeys of the present study may have resulted from the cross-reactivity of DENV antibodies, and this cross-reactivity may be caused by repeated DENV infections within these monkeys. Therefore, the specificity of these antibodies to ZIKV needs to be further characterized by more sensitive and specific assays, such as detecting the antibodies against ZIKV NS1, which would be a better signal of ZIKV infection. ${ }^{28-30}$ Antibodies against CHIKV were also observed in a long-tailed macaque living in Mo Ko Chang, located in the south of Thailand, suggesting enzootic transmission in that region. In fact, CHIKV-infected human cases have been intensively reported from the south of Thailand. ${ }^{31}$ The outbreaks of CHIKV in the south of Thailand during 2008-2009 ${ }^{32,33}$ and the number of CHIKV-infected cases declined before reemerging again in $2018 .^{34,35}$ In Thailand in 2018, the outbreak of CHIKV was not only reported in the south but also in several provinces including Bangkok. Therefore, the presence of CHIKV antibodies in the monkeys from Mu ko Ranong, located in the south of Thailand, correlates with the incidences of CHIKVinfected human cases. The low seroprevalence rate of $\mathrm{CHIKV}$ was also reported in Malaysia, where $1 \%$ of $\mathrm{CHIKV}$-seropositive cases were determined in long-tailed macaques in Malaysia. ${ }^{36,37}$

In summary, evidence of arboviral infections was found in wild macaques living in the national parks of Thailand. However, it should be noted that the study included a broad sampling of different NHP species. Limitations of the study include restricted geographical coverage and a varied number of samples per site. Establishing an arboviral infection rate and foci for vector transmission combined with findings from seroprevalence studies as well as investigating the sylvatic transmission and reservoir potential of ZIKV, DENV, and $\mathrm{CHIKV}$ of NHPs proximal to human populations would allow for a more comprehensive understanding of the role of enzootic arboviral circulation.

Received January 21, 2020. Accepted for publication May 5, 2020.

Published online June 22, 2020.

Note: Supplemental table appears at www.ajtmh.org.

Financial support: The study was financially supported by the National Science and Technology Development Agency, Thailand, through the eAsia joint research program and Faculty of Veterinary Medicine, Kasetsart University.

Authors' addresses: Daraka Tongthainan, Bio-Veterinary Sciences Program, Faculty of Veterinary Medicine, Kasetsart University, Bangkok, Thailand, E-mail: daodaraka@gmail.com. Nanthanida Mongkol, Kultida Jiamsomboon, Sarocha Suthisawat, and Kobporn Boonnak, Department of Microbiology and Immunology, Faculty of Tropical Medicine, Mahidol University, Bangkok, Thailand, E-mails: nanthanida@ outlook.com, kultidacare@gmail.com, faisuthisawat@gmail.com, and kboonnak@gmail.com or kobporn.boo@mahidol.ac.th. Pornchai Sanyathitiseree, Department of Livestock and Wildlife Medicine, Faculty of Veterinary Medicine, Kasetsart University, Bangkok, Thailand, E-mail: fvetpos@ku.ac.th. Manakorn Sukmak, Department of Farm Resources and Production Medicine, Faculty of Veterinary Medicine, Kasetsart University, Bangkok, Thailand, E-mail: fvetmksu@gmail.com. Worawidh Wajjwalku, Faculty of Veterinary Medicine, Kasetsart University, Bangkok, Thailand, E-mail: fvetwww@yahoo.com. Yong Poovorawan, Center of Excellence in Clinical Virology, Faculty of Medicine, Chulalongkorn University, Bangkok, Thailand, E-mail: yong.p@chula.ac.th. Gittiyaporn leamsaard, Bencharong Sangkharak, and Kanokwan Taruyanon, Department of National Park Wildlife and Plant Conservation, Bangkok, Thailand, E-mails: myway1435@gmail.com, vacuummm@hotmail.com, and kanokwanvet@hotmail.com. Wirasak Fungfuang, Department of Zoology, Faculty of Science, Kasetsart University, Bangkok, Thailand, E-mail: fvetpnt@ku.ac.th. Phitsanu Tulayakul, Department of Veterinary Public Health, Faculty of Veterinary, Kasetsart University, Thailand, E-mail: fvetpnt@ku.ac.th.

\section{REFERENCES}

1. Jones KE, Patel NG, Levy MA, Storeygard A, Balk D, Gittleman JL, Daszak P, 2008. Global trends in emerging infectious diseases. Nature 451: 990-993.

2. Vasilakis N, Cardosa J, Hanley KA, Holmes EC, Weaver SC, 2011. Fever from the forest: prospects for the continued emergence of sylvatic dengue virus and its impact on public health. Nat Rev Microbiol 9: 532-541.

3. Weaver SC, 2005. Host range, amplification and arboviral disease emergence. Arch Virol Suppl 19: 33-44.

4. Weaver SC, Barrett AD, 2004. Transmission cycles, host range, evolution and emergence of arboviral disease. Nat Rev Microbiol 2: 789-801.

5. Valentine MJ, Murdock CC, Kelly PJ, 2019. Sylvatic cycles of arboviruses in non-human primates. Parasit Vectors 12: 463.

6. Kuno G, Chang GJ, 2005. Biological transmission of arboviruses: reexamination of and new insights into components, mechanisms, and unique traits as well as their evolutionary trends. Clin Microbiol Rev 18: 608-637.

7. Timiryasova TM, Bonaparte MI, Luo P, Zedar R, Hu BT, Hildreth SW, 2013. Optimization and validation of a plaque reduction neutralization test for the detection of neutralizing antibodies to four serotypes of dengue virus used in support of dengue vaccine development. Am J Trop Med Hyg 88: 962-970.

8. Roehrig JT, Hombach J, Barrett AD, 2008. Guidelines for plaquereduction neutralization testing of human antibodies to dengue viruses. Viral Immunol 21: 123-132.

9. Lai CY, Tsai WY, Lin SR, Kao CL, Hu HP, King CC, Wu HC, Chang GJ, Wang WK, 2008. Antibodies to envelope glycoprotein of dengue virus during the natural course of infection are predominantly cross-reactive and recognize epitopes containing highly conserved residues at the fusion loop of domain II. J Virol 82: 6631-6643.

10. Luo YY, Feng JJ, Zhou JM, Yu ZZ, Fang DY, Yan HJ, Zeng GC, Jiang LF, 2013. Identification of a novel infection-enhancing epitope on dengue prM using a dengue cross-reacting monoclonal antibody. BMC Microbiol 13: 194.

11. Ward MJ et al., 2018. Zika virus and the world health Organization criteria for determining recent infection using plaque reduction neutralization testing. Am J Trop Med Hyg 99: 780-782.

12. WHO, 2016. Zika virus infection: global update on epidemiology and potentially associated clinical manifestations. Wkly Epidemiol Rec 91: 73-81.

13. Apandi Y, Lau SK, Izmawati N, Amal NM, Faudzi Y, Mansor W, Hani MH, Zainah S, 2010. Identification of chikungunya virus strains circulating in Kelantan, Malaysia in 2009. Southeast Asian J Trop Med Public Health 41: 1374-1380.

14. Buechler CR et al., 2017. Seroprevalence of zika virus in wild African green monkeys and baboons. mSphere 2: e00392-16.

15. Vasilakis N, Durbin AP, da Rosa AP, Munoz-Jordan JL, Tesh RB, Weaver SC, 2008. Antigenic relationships between sylvatic and endemic dengue viruses. Am J Trop Med Hyg 79: 128-132.

16. Wang E, Ni H, Xu R, Barrett AD, Watowich SJ, Gubler DJ, Weaver SC, 2000. Evolutionary relationships of endemic/epidemic and sylvatic dengue viruses. J Virol 74: 3227-3234.

17. Vasilakis N, Tesh RB, Weaver SC, 2008. Sylvatic dengue virus type 2 activity in humans, Nigeria, 1966. Emerg Infect Dis 14: 502-504.

18. Althouse BM et al., 2018. Role of monkeys in the sylvatic cycle of chikungunya virus in Senegal. Nat Commun 9: 1046.

19. Althouse BM, Durbin AP, Hanley KA, Halstead SB, Weaver SC, Cummings DA, 2014. Viral kinetics of primary dengue virus infection in non-human primates: a systematic review and individual pooled analysis. Virology 452-453: 237-246.

20. Chen CI, Clark DC, Pesavento P, Lerche NW, Luciw PA, Reisen WK, Brault AC, 2010. Comparative pathogenesis of epidemic 
and enzootic chikungunya viruses in a pregnant Rhesus macaque model. Am J Trop Med Hyg 83: 1249-1258.

21. Dudley DM et al., 2016. A rhesus macaque model of Asian-lineage Zika virus infection. Nat Commun 7: 12204

22. Hanley KA, Guerbois M, Kautz TF, Brown M, Whitehead SS, Weaver SC, Vasilakis N, Marx PA, 2014. Infection dynamics of sylvatic dengue virus in a natural primate host, the African Green Monkey. Am J Trop Med Hyg 91: 672-676.

23. Nakgoi K, Nitatpattana N, Wajjwalku W, Pongsopawijit P, Kaewchot S, Yoksan S, Siripolwat V, Souris M, Gonzalez JP, 2014. Dengue, Japanese encephalitis and chikungunya virus antibody prevalence among captive monkey (Macaca nemestrina) colonies of northern Thailand. Am J Primatol 76: 97-102.

24. Dubot-Peres A et al., 2013. An epidemic of dengue-1 in a remote village in rural Laos. PLoS Negl Trop Dis 7: e2360.

25. Teoh BT, Sam SS, Abd-Jamil J, AbuBakar S, 2010. Isolation of ancestral sylvatic dengue virus type 1, Malaysia. Emerg Infect Dis 16: 1783-1785.

26. Chua CL, Chan YF, Andu E, Rovie-Ryan JJ, Sitam FT, Verasahib $\mathrm{K}$, Sam IC, 2019. Little evidence of Zika virus infection in wild long-tailed macaques, peninsular Malaysia. Emerg Infect Dis 25: $374-376$.

27. Ruchusatsawat K, Wongjaroen $\mathrm{P}$, Posanacharoen A, RodriguezBarraquer I, Sangkitporn S, Cummings DAT, Salje H, 2019. Long-term circulation of Zika virus in Thailand: an observational study. Lancet Infect Dis 19: 439-446.

28. Speer SD, Pierson TC, 2016. Virology. Diagnostics for Zika virus on the horizon. Science 353: 750-751.

29. Balmaseda A et al., 2017. Antibody-based assay discriminates Zika virus infection from other flaviviruses. Proc Natl Acad Sci USA 114: 8384-8389.

30. Sharp TM, Fischer M, Munoz-Jordan JL, Paz-Bailey G, Staples JE, Gregory CJ, Waterman SH, 2019. Dengue and zika virus diagnostic testing for patients with a clinically compatible illness and risk for infection with both viruses. MMWR Recomm Rep 68: 1-10.

31. Javelle $E$ et al., 2019. Increased risk of chikungunya infection in travellers to Thailand during ongoing outbreak in tourist areas: cases imported to Europe and the middle east, early 2019. Euro Surveill 24: 1900146.

32. Rianthavorn $\mathrm{P}$, Prianantathavorn $\mathrm{K}$, Wuttirattanakowit $\mathrm{N}$, Theamboonlers A, Poovorawan Y, 2010. An outbreak of chikungunya in southern Thailand from 2008 to 2009 caused by African strains with A226V mutation. Int J Infect Dis 14 (Supp/3): e161-e165.

33. Theamboonlers A, Rianthavorn P, Praianantathavorn K, Wuttirattanakowit N, Poovorawan Y, 2009. Clinical and molecular characterization of chikungunya virus in south Thailand. Jpn J Infect Dis 62: 303-305.

34. Chansaenroj J, Wanlapakorn N, Ngamsaithong C, Thongmee T, Na Nakorn N, Siriyasatien P, Vongpunsawad S, Poovorawan Y, 2019. Genome sequences of chikungunya virus isolates from an outbreak in southwest Bangkok in 2018. Arch Virol 165: 445-450.

35. Intayot $P$, Phumee A, Boonserm R, Sor-Suwan S, Buathong R, Wacharapluesadee S, Brownell N, Poovorawan Y, Siriyasatien $P, 2019$. Genetic characterization of chikungunya virus in fieldcaught Aedes aegypti mosquitoes collected during the recent outbreaks in 2019, Thailand. Pathogens 8: 121.

36. Marchette NJ, Rudnick A, Garcia R, 1980. Alphaviruses in peninsular Malaysia: II. Serological evidence of human infection. Southeast Asian J Trop Med Public Health 11: 14-23.

37. Sam IC, Chua CL, Rovie-Ryan JJ, Fu JY, Tong C, Sitam FT, Chan YF, 2015. Chikungunya virus in macaques, Malaysia. Emerg Infect Dis 21: 1683-1685. 